\title{
O Debate sobre a diferença de classe no SUS
}

\section{Alethele de Oliveira Santos ${ }^{1}$, Fernando Passos Cupertino de Barros ${ }^{2}$, Silvia Badim Marques $^{3}$}

\section{Introdução}

O fenômeno da Judicialização das Políticas de Saúde vem ganhando importância teórica e prática ao desencadear debates pungentes entre acadêmicos, operadores do direito, gestores públicos e sociedade civil. Trouxe para o centro dessa arena a atuação do Poder Judiciário em relação à garantia do direito social à saúde, que demanda para tanto, políticas públicas de prestação de serviços de saúde por parte do Estado.

Esse fenômeno não é uma característica exclusiva do Brasil. Gloppen (2005) salienta que as decisões judiciais em matéria de direitos sociais, como o direito à saúde, têm acarretado consequências políticas e econômicas, principalmente nos países em desenvolvimento, dadas as características intrinsecamente imbricadas com questões emanadas de políticas e orçamentos públicos, concordando, portanto com as teses apresentadas por outros autores (YEPES, 2007; VARGAS, 2010).

Lopes (2004) salienta que em países de economia periférica e de estados sociais de direito incompletos, os Tribunais têm assumido papel importante na distribuição de bens e recursos coletivos "sejam eles os tradicionais direitos de bem-estar social (educação, saúde, previdência e assistência social), sejam os custos econômicos e financeiros da vida em comum" (p. 197).

No Brasil o direito à saúde decorre da leitura expressa da Constituição Federal, principalmente dos artigos 196 a 200. Todavia a interpretação do artigo 196 denota teses antagônicas, que põe em confronto: o 'mínimo existencial', a 'reserva do possível' e a

\footnotetext{
${ }^{1}$ Advogada, mestre em Saúde Coletiva pela UnB, Assessora Técnica do Conselho Nacional de Secretários de Saúde-CONASS. Brasília, Brasil. E-mail: alethele.santos@conass.org.br

${ }^{2}$ Médico, mestre em Saúde Coletiva pelo ISC-UFBA e doutorando em Saúde Coletiva FSC-UnB; Professor assistente da Faculdade de Medicina da UFG; Assessor técnico do Conselho Nacional de Secretários de Saúde-CONASS. Brasília, Brasil. E-mail: fernando.cupertino@conass.org.br

${ }^{3}$ Bacharel em Direito, mestre e doutora em Saúde Pública pela Universidade de São Paulo - USP. Professora adjunta da Universidade de Brasília - UnB, Faculdade de Ceilândia. Brasília, Brasil. E-mail: sbadim@gmail.com
} 
'proibição do retrocesso social', além de discutir os limites financeiros e operacionais para a garantia deste direito. Isto porque o direito à saúde, para ser exercido, depende da existência de uma ampla gama de políticas e serviços estatais, que por sua vez dependem de uma série de fatores políticos e financeiros para serem efetivados.

Barcelos (2001) apresenta o mínimo existencial como precedente do princípio da dignidade da pessoa humana, segundo o qual o Estado deve oferecer aos cidadãos um núcleo básico de prestações e serviços, considerados pela autora como elementos materiais mínimos da dignidade, sem os quais se poderá afirmar que o indivíduo se encontra em situação de indignidade.

Já para a Reserva do Possível, Barcelos (2001) indica que pode ser fática quando aproxima-se da exaustão orçamentária, admitido questionamento dessa realidade, tendo em vista as formas de arrecadação e a natureza de ingressos públicos. Pode ser jurídica, quando não há propriamente um estado de exaustão e sim, ausência de autorização para determinado gasto.

No que se refere à Proibição do Retrocesso Social, Cunha (2010) salienta que um dos conceitos mais bem formulados sobre este princípio foi elaborado por Felipe Derbli (2007, p.59):

Diz que o princípio tem teleologicamente a função de garantir o grau de concretização dos direitos fundamentais sociais e, mais que isso, a permanente obrigação constitucional de desenvolver essa concretização, não permitindo, de forma alguma, que se retroceda a um quadro sóciojurídico já esgotado, distante do ideal proposto pela Carta Magna.

Portanto, de um lado o direito à saúde é erigido do ordenamento jurídico como um direito integral e universal, de aplicabilidade imediata, que deve garantir aos cidadãos todos os cuidados que necessitam para a proteção, promoção e recuperação de sua saúde. De outro os limites intrínsecos, para os quais há um direito que demanda organização política, recursos e bens públicos para a sua garantia.

Isso evidencia que a complexidade das questões que envolvem a garantia do direito à saúde extrapola o próprio contorno do sistema jurídico, levando o órgão central desse sistema, o Poder Judiciário, a reconhecer que o mero exame do arcabouço legal, através das técnicas de interpretação e aplicação do direito posto, não se revelam capazes de solucionar as demandas sanitárias que lhes são submetidas. 
A Suprema Corte brasileira vem se manifestando sobre diversos temas que envolvem a garantia do direito à saúde e utiliza-se das audiências públicas para ouvir os mais diversos interessados e especialistas nos temas sob julgamento, com o intuito de formar seus juízos e fundamentar suas decisões. Assim procedeu, quando o STF foi chamado a manifestar-se sobre processos judiciais que demandam medicamentos de alto custo, bem como outras prestações de saúde por parte do Estado e que culminou na decisão do Ministro Gilmar Mendes para a Suspensão de Tutela Antecipada 175 (STA 175, 2009).

Da mesma forma, no ano 2013, em face das Ações Direitas de Inconstitucionalidade (ADI) 5035 e 50374, que contestaram dispositivos da Medida Provisória (MP) 621/2013 (convertida na lei n. 12.871/2013) que instituiu o programa o Programa Mais Médicos, o STF convocou audiência pública, presidida pelo Ministro Marco Aurélio de Mello.

Em maio de 2014, mediante convocação do Ministro Dias Toffoli, foi realizada audiência pública para a oitiva de especialistas, no que foi denominado 'diferença de classe' no SUS, por ser tema que apresenta relevância jurídica e social, por envolver debates jurídicos importantes, reclamar análise que ultrapassa os limites do estritamente jurídico, requerendo abordagens técnicas sobre seu impacto administrativo e econômico, dos seus efeitos nos procedimentos de triagem e no acesso ao SUS.

A temática da diferença de classe persegue mais que a garantia do direito à saúde. Persegue, na verdade, o modelo de sistema de saúde universal e igualitário estruturado no Brasil com a Constituição Federal de 1988 (CF/88), bem como a forma em que este modelo oferta ações e serviços de assistência médica e hospitalar à população brasileira.

A discussão da diferença de classe, no âmbito do STF, decorre do reconhecimento de repercussão geral ${ }^{5}$ acerca do Recurso Extraordinário (RE) 581488 interposto contra

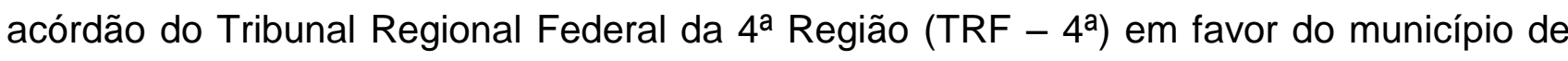
Canela (RS) - que proibiu esse tipo de pagamento.

\footnotetext{
${ }^{4}$ As citadas ações foram apresentadas pela Associação Médica Brasileira (AMB) e pela Confederação Nacional dos Trabalhadores Universitários Regulamentados (CNTU), respectivamente, com o intuito de questionar, principalmente, a dispensa da exigência de revalidação dos diplomas dos médicos formados em universidades estrangeiras e a contratação destes profissionais através de bolsas.

${ }^{5}$ Instrumento processual cuja análise de mérito da questão apresentada gera decisão que passa a ser utilizada nos casos idênticos por instâncias inferiores.
} 
O TRF-4 julgou a referida ação improcedente, por entender que esse tipo de pagamento, mesmo sem ônus para o Estado, confere tratamento diferenciado aos pacientes dentro do SUS, um sistema que se pretende universal e igualitário e tem como diretriz a redução das desigualdades sociais em saúde. O Cremers, por sua vez, ao questionar a decisão do TRF-4 em Recurso Extraordinário (RE 581488) fez com que o STF optasse por realizar a Audiência Pública em comento.

Espera-se que a análise da Audiência em comento, possibilite ao Ministro Dias Tofolli e aos demais ministros da Suprema Corte, encontrarem respostas às seguintes perguntas: (i) é lícito o poder público instituir dentro do SUS co-pagamento para que determinados cidadãos, que podem arcar com estes valores, possam ter acesso diferenciado a bens e serviços de saúde? (ii) a inserção de co-pagamento tem fundamento legal consubstanciado nos preceitos constitucionais que regem o SUS? (iii) o copagamento, que diferencia o acesso à saúde, feriria o princípio constitucional da igualdade de acesso ao SUS, bem como a gratuidade das prestações de saúde previstas na lei complementar n.141/12 e no artigo 43 da Lei n. 8.080/90?

\section{Da diferença de classe: histórico e legalidade}

O termo diferença de classe foi cunhado para estabelecer a possibilidade de pagamento - portanto direito destinado aos indivíduos pertencentes a uma classe economicamente mais abastada - por acesso a serviços de profissionais médicos ou hotelaria diferenciada, dentro do Sistema Público de Saúde, em detrimento daqueles que não possam custear tais valores.

A saúde, a partir das constituições pátrias, foi gradativamente erigida à condição de direito fundamental. Na constituição de 1946 há menção à gratuidade da política maternoinfantil. Já em 1967, conforme o artigo 165 em seu inciso XV é possível distinguir a ampliação da assistência à saúde, a partir da menção dos termos assistência sanitária, hospitalar e médico preventiva, todavia, mantida, exclusivamente, aos trabalhadores assim registrados em carteira de trabalho.

Segundo Viana, Piola e Reis (1998), por não haver até então, qualquer vedação constitucional ao co-pagamento, houve em 1967, a sua primeira tentativa de adoção, com - Plano Nacional de Saúde (PNS), denominado pelos autores como ensaio de "privatização selvagem do setor" (op.cit. p.119) e que após o fracasso das experiências 
piloto, foi abandonado. A tentativa seguinte, em 1974, consistiu numa tabela nacional de participação financeira para o custeio da saúde, segundo diferentes classes de renda da população, que estava embutida no Plano de Pronta Ação do Ministério da Previdência e Assistência Social (MPAS) e que facultava aos beneficiários do Instituto Nacional da Previdência Social (INPS) a opção por instalações hospitalares especiais, nos hospitais privados contratados. Interessa destacar a exposição dos autores:

O necessário sobrepreço nas diárias de hotelaria dos pacientes que optassem por esse tipo de acomodação veio acompanhado da exigência de complementação dos honorários profissionais em até $100 \%$ do preço pago pelo INPS, para atender ao pleito da corporação médica. (op.cit. p. 120).

Segundo os mesmos autores, a terceira tentativa deu-se quando o Congresso Nacional, na lei o 6.429 , de $1^{\circ}$ de setembro de 1977, que criou o Sistema Nacional de Previdência e Assistência Social (SINPAS) e o Instituto Nacional de Assistência Médica e Previdência Social (INAMPS) - autorizou o Poder Executivo a instituir, no âmbito da previdência social, a participação direta dos beneficiários no custeio dos serviços médicos e dos medicamentos fornecidos em ambulatório. A lei indicou ainda que deveriam ser observados os níveis de renda do paciente e outros fatores como o vulto das despesas e a natureza da doença. As isenções estiveram restritas aos segurados estatais, aos acidentados no trabalho e àqueles que recebessem - por remuneração ou benefício - até cinco vezes os valores de referência. Ainda que tal possibilidade não tenha sido implementada, chegou a ser considerada pela Secretaria de Planejamento (SEPLAN) durante a crise previdenciária da década de 1980.

Com a edição das portarias do Ministério da Previdência e Assistência Social (MPAS) ํo 2.079 de 1980 e Portaria ํo 2.837 de 1982, o uso de instalações especiais voltou a ser regulamentado, na medida em que previu que os valores pagos a título da diferença de classe não poderiam ultrapassar o valor estabelecido pela Associação Médica Brasileira (AMB), o que persistiu até dezembro de 1986, quando o MPAS liberou a complementação financeira, a partir de livre negociação entre médico e paciente.

Em 1991, com a edição da Portaria INAMPS no 283, houve proibição definitiva da prática de complementação de honorários médicos e por serviços diferenciados de hotelaria, o que foi ratificado pela Portaria do Ministério da Saúde n. 113 de 04 de setembro de 1997. 
Cumpre informar que a dúvida acerca da proibição mencionada, persistiu, conforme exposto em documento da Câmara dos Deputados, da lavra do Deputado Rogério Silva, do ano 2001, pelo fato de que a CF/88 não trouxe referência expressa à gratuidade do direito à saúde, a despeito de indicá-lo como dever do Estado.

Assim, o debate sobre a legalidade da instituição da 'diferença de classe' fundamentou-se em três pontos principais:

- nem todos os direitos sociais são acompanhados da gratuidade ao cidadão como o caso da previdência social, também pertencente ao sistema de seguridade social;

- a assembleia constituinte grafou de forma inequívoca a gratuidade para a educação, ainda que o artigo 205 da CF/88 também tivesse a expressão direito de todos e dever do Estado;

- o artigo 195 da CF/88 previu que a seguridade social, na qual está incluída a saúde, deve ser financiada de forma direta e indireta.

$\mathrm{Na}$ tentativa de dirimir tais controvérsias, é preciso buscar os posicionamentos da Corte Constitucional Brasileira sobre o direito à saúde. Para o STF, conforme se apreende da decisão da STA 175, a CF/88 prevê a existência de direitos fundamentais sociais, especifica seu conteúdo e forma de prestação, não faz distinção entre os direitos e deveres individuais e coletivos e os direitos sociais, e estabelece que os direitos e garantias fundamentais tenham aplicação imediata.

Sendo a análise das demandas pelo direito à saúde, orientada a partir do contexto constitucional, compete apresentar a interpretação do artigo 196 da CF/88, feita pelo STF, exarada após a audiência pública da saúde, na decisão já mencionada. Por 'direito de todos', o STF entendeu tratar-se tanto o direito individual quanto o direito coletivo à saúde, assegurado à generalidade das pessoas e que conduz o indivíduo e o Estado a uma relação jurídica obrigacional, estando legitimado o Poder Judiciário a atuar nas hipóteses em que a Administração Pública descumpra a ordem constitucional.

Acerca da expressão dever do Estado o entendimento foi de que há, por parte do Estado Brasileiro, o dever fundamental de prestação de saúde e que o SUS, em sua conformação, descentralizou ações e serviços de saúde e conjugou recursos financeiros dos entes para aumentar, qualificar e garantir o acesso. 
Em sendo direito de todos e dever do Estado, compreendeu o STF, que este direito deve ser garantido mediante políticas sociais e econômicas que visem à redução do risco de doença e de outros agravos, de forma a evidenciar sua dimensão preventiva. Indicou que a necessidade de formulação de políticas públicas que concretizem o direito à saúde se dá por meio de escolhas alocativas e com a utilização de critérios distributivos.

Quanto à expressão políticas que visem à redução do risco de doença e de outros agravos indicou a sua priorização expressa no artigo 198, inciso II, da Constituição. A expressão políticas que visem acesso universal e igualitário foi entendida como aquela que se refere à efetivação de políticas públicas para a população como um todo, exequíveis igualmente, livres de preconceitos e privilégios.

Por fim, para a expressão ações e serviços para promoção, proteção e recuperação da saúde estabeleceu que as demandas que versem sobre o direito à saúde devem ser vistas à luz da CF/88, que prevê a existência de direitos fundamentais sociais, especifica conteúdo e forma de prestação, ou seja, mediante ações e serviços de saúde, executados de forma descentralizada, constante de instrumentos de planejamento, acompanhados pelo controle social e conforme financiamento tripartite.

Assim, numa interpretação sistemática do conjunto de itens que compõem o artigo 196 da CF/88 é possível asseverar que o direito à saúde é tanto individual quanto coletivo, deve ser suprido pelo Estado, a partir da conjugação de esforços financeiros de todos os entes federados, mediante políticas sociais e econômicas que visem reduzir o risco de doença e outros agravos. Sob a guarda do acesso universal e igualitário - todos devem acessar de forma idêntica a política de saúde da qual necessitam, mediante as ações e serviços de saúde, excluídos discriminação ou privilégio.

A interpretação constitucional do artigo 196 trazida pelo STF seria suficiente para fundamentar a inadmissibilidade da diferença de classe no território nacional. Ainda assim, zelando pela boa interpretação normativa, cumpre verificar a intenção do legislador numa análise mais sistemática e não apenas em artigo constitucional específico.

$\mathrm{Na}$ hipótese de que os ditames constitucionais não sejam considerados suficientes para o entendimento da impossibilidade da diferença de classe no Brasil, interessa, por critério de antiguidade, primeiramente a Lei n. 8.080/90 - Lei Orgânica da Saúde.

Seu artigo $7^{0}$ reconhece a necessidade que as ações e serviços públicos de saúde do SUS - quer sejam praticados pela Administração quer por particular (em decorrência de 
relação contratual), obedeçam aos princípios da universalidade de acesso, com igualdade na assistência. O pleito de que seja acatada possibilidade de pagamento diferenciado por serviços de hotelaria e do profissional médico está em flagrante confronto com os princípios que regem o direito à saúde.

Sua admissibilidade, requerida por categoria profissional, configura a supremacia do interesse privado em detrimento do público. Para a atuação da iniciativa privada há regras a serem seguidas:

A autonomia privada, que encontra claras limitações de ordem jurídica, não pode ser exercida em detrimento ou com desrespeito aos direitos e garantias de terceiros, especialmente aqueles positivados em sede constitucional, pois a autonomia da vontade não confere aos particulares, no domínio de sua incidência e atuação, o poder de transgredir ou de ignorar as restrições postas e definidas pela própria Constituição, cuja eficácia e força normativa também se impõem, aos particulares, no âmbito de suas relações privadas, em tema de liberdades fundamentais. ( $\underline{R E}$ 201.819, Rel. p/ o ac. Min. Gilmar Mendes, julgamento em 11-102005, Segunda Turma, DJ de 27-10-2006).

Mais ainda. O artigo 43 da Lei n. 8.080/90 dispõe expressamente que "A gratuidade das ações e serviços de saúde fica preservada nos serviços públicos contratados, [...]" vedando a cobrança de quaisquer valores para que o usuário acesse o SUS e utilize quaisquer de seus serviços, sejam eles médicos, de hotelaria, de diagnóstico, de tratamento, etc. Em tese, a associação dos dispositivos constitucionais aos da legislação ordinária, seriam suficientes para elucidar dúvida existente acerca da inadmissibilidade da diferença de classe.

Todavia, ao considerar que foi tomada de importância significativa a ausência da palavra 'gratuidade' para as ações e serviços de saúde na ordem constitucional, cumpre mencionar a lei complementar n. 141/12 (LC 141), cujo artigo 2ํe estabeleceu, além dos princípios contidos na lei n. 8.080/90, que somente ações e serviços de saúde que sejam de acesso universal e gratuito, podem ser considerados como despesas públicas em saúde. Conclui-se então que ações e serviços de saúde que, porventura, admitam copagamento não são universais, não são gratuitos e, portanto, não podem ser classificadas como despesas públicas em saúde.

Ainda nesse diapasão, revisada a legislação sanitária, constata-se que não há previsão legal que permita à Administração Pública pagamento de parte de ação ou 
serviço público de saúde, conforme pretende a diferença de classe, o que, consequentemente impede a Administração de fazê-lo.

Tal interpretação encontra fundamento no princípio da legalidade a que está vinculada a Administração Pública, conforme preconiza o artigo 37 da CF/88, ou seja, há uma submissão do Estado à lei em toda a sua atividade funcional, dela não podendo desviar-se ou afastar-se, sob pena de praticar ato inválido e expor-se à responsabilidade administrativa, civil e criminal, conforme previsto no artigo $2^{\circ}$ da Lei 9.784/99.

Desta feita, consideradas a CF/88, a lei n. 8080/90, a lei complementar n. 141/12 e os princípios que regem a Administração Pública, não foi encontrado fundamento legal que permita a admissibilidade da 'diferença de classe' nas ações e serviços públicos de saúde.

\section{A diferença de classe e os modelos de sistemas de saúde}

Há que se perceber que a diferença de classe foi permitida no Brasil numa época em que o modelo organizativo estatal para a saúde era muito diferente do atual. Esta prática mostrou-se inadequada às pretensões da sociedade brasileira, a ponto de jazer completamente, no modelo estabelecido pela CF/88.

Os especialistas em sistemas de saúde chamariam a admissão da diferença de classe de co-pagamento, o que estaria mais relacionado a um modelo de sistema de saúde em que a proteção é destinada aos que podem pagar ou aos que têm vínculo empregatício formal e que foi representado no Brasil, pelo que era oferecido pelo INAMPS/MPAS. Todavia, a atual CF/88, com bases no Estado de bem estar social, estabelece a adoção do sistema de saúde de assistência universal, igualitário, livre de preconceitos e privilégios, fundamentado na solidariedade. A CF/88, contudo, admitiu, para além do SUS, a atuação da iniciativa privada na saúde, criando, consequentemente, um sistema misto.

A atuação da iniciativa privada na saúde pode dar-se de formas distintas: mediante atuação de estabelecimentos e profissionais de saúde, remunerados por desembolso direto dos pacientes; pela oferta de ações e serviços disponibilizada por operadoras/planos de saúde, mediante remuneração mensal de pessoa física ou jurídica, em conformidade com as regras expedidas pela agência reguladora do setor (Agência Nacional de Saúde Suplementar - ANS); ou ainda, mediante a prestação de serviços ao SUS, conforme 
instrumento jurídico adequado, em que perceberá remuneração avençada em instrumento e passará a figurar como agente público na oferta de ações e serviços de saúde.

A legislação admitiu que a iniciativa privada atue no setor saúde, portanto, aqueles profissionais médicos que queiram oferecer atendimento clínico ou especializado, ou estabelecimentos hospitalares que queiram dispor de hotelaria diferenciada nos casos de internação devem ser remunerados por desembolso direto dos pacientes ou por operadoras de planos/seguros de saúde que atuam na saúde suplementar, conforme regulação contratual.

Assim considerando, admitir a diferença de classe é alterar o modelo do sistema de saúde constitucionalmente estabelecido, criando para além das possibilidades legalmente expressas, a modalidade do co-pagamento dentro do sistema público, cujas vedações legais já foram apresentadas.

\section{A diferença de classe e sua incompatibilidade com o modelo organizativo do SUS}

\section{Dos profissionais médicos}

Ao considerar o RE 581488, há que se crer que os interesses, tais quais foram em tempos anteriores à CF/88, continuam corporativos, isto por inexistir na lide, a representação dos usuários do SUS enquanto requerentes.

Sendo a diferença de classe, requerida sob a manifestação de interesses corporativos, carece de respostas que fazem pensar nos impactos sociais, econômicos e jurídicos de sua admissibilidade: (i) nos dias de hoje há normativa legal sobre honorários médicos? De que forma é cumprida? (ii) qual a forma de controle existente sobre seu cumprimento? (iii) há publicização desta regulamentação, assim como, das penalidades pelo seu descumprimento? (iv) os pacientes e/ou seus familiares, já submetidos à desvantagem da doença, têm condição de proceder à aferição de tabela de honorários ou ainda recusar o atendimento em caso de descumprimento da mesma? (v) pacientes, portanto já em estado de vulnerabilidade pela doença, têm condições de negociar preços com os profissionais e estabelecimentos? A história mostra que depois da tabela vem a livre negociação.

Como não bastassem tais indagações, pergunta-se ainda: (i) há no Brasil, profissionais médicos em número suficiente para suprir as necessidades do SUS e das 
operadoras de plano/seguro de saúde? (ii) admitida a diferença de classe estes profissionais se vinculariam aos sistemas público ou suplementar ou àquele em que cobrariam por seu trabalho valores financeiros negociados diretamente com os pacientes? (iii) os médicos vinculados ao SUS permaneceriam proibidos de praticar a cobrança permitida na diferença de classe - mesmo nos casos em que haja disponibilidade horária para a prática da medicina em consultório privado e consequente prescrição de internação hospitalar?

Para além dos impactos sociais, econômicos e jurídicos, a diferença de classe tratase de questão com impactos políticos e éticos na atuação dos profissionais médicos. A resposta que se apresenta é que a atuação do profissional médico não pode e nem deve diferenciar-se em seu cuidado, desvelo e dedicação ao paciente, a partir do recebimento de honorários.

\section{Da hotelaria hospitalar}

A oferta de leitos hospitalares no Brasil é, majoritariamente, oriunda da rede privada - filantrópica ou não. Em geral, estes leitos servem, às internações pagas mediante desembolso direto, por planos/seguradoras de saúde e pelo SUS. Quando os leitos são adquiridos pelo SUS, mediante instrumentos que estabelecem relações contratuais entre o público e o privado, observadas as prioridades determinadas pela lei, passam a ser regulados - ou seja, têm acesso controlado - pelo gestor local de saúde. É o que se reconhece, em jargão sanitário, por regulação de acesso.

É bem sabido que a hotelaria hospitalar trata-se de segmento econômico rentável, especialmente quando refere leitos especializados ou de tratamento intensivo. Tanto o SUS quanto as operadoras de planos/seguros de saúde possuem instrumentos reguladores de preços para aquisição de leitos - o que por óbvio não se aplica aos casos do desembolso direto ou de eventual diferença de classe.

Pergunta-se então: (i) haveria oferta de leitos ao SUS ou aos planos/operadoras de saúde, sabendo-se que, na 'diferença de classe' seu preço seria negociado diretamente com o paciente ou sua família? (ii) de quem é a responsabilidade pela regulação de preços, no mercado, a serem cobrados a título de hotelaria diferenciada? (iii) quais seriam os critérios considerados por 'melhor acomodação' nas acomodações comuns ou nas unidades/centros de tratamento intensivo? 
Em meio a tantas perguntas, talvez apenas uma resposta seja evidente: ao SUS não seria mais possível adquirir leitos de prestadores privados filantrópicos ou não. Menor possibilidade ainda existiria para a regulação de acesso aos pacientes SUS, uma vez que os estabelecimentos hospitalares, com vistas às regras de mercado promoveriam ofertas, exclusivamente, aos que melhor pagassem. Já à saúde suplementar restaria arcar com aumentos vertiginosos nos preços - determinados pela luta de mercado - o que consequentemente seria repassado aos clientes/segurados. Aos pacientes e seus familiares, vulneráveis pela doença, caberia - necessitados de internação hospitalar submeterem-se aos preços praticados no estabelecimento.

Este não é um cenário viável no Estado Social, cuja constituição determina que a saúde seja obrigação estatal.

\section{Da redução dos custos no SUS e a moderação da demanda: estratégia inadequada}

Aos desavisados poderia parecer que a participação financeira do paciente no custo do tratamento, poderia gerar tanto a disponibilidade de recursos para o SUS, quanto moderação da demanda.

Todavia, ao considerar a hipótese que a desoneração do SUS nos custos com médicos e hotelaria poderia gerar incremento no acesso, a diferença de classe não leva em consideração que: (i) já há no Brasil um mercado concorrencial - entre o SUS, a saúde suplementar e os que pagam diretamente aos médicos e hospitais; (ii) a inclusão de uma nova possibilidade de atuação do sistema público, o co-pagamento, acarretaria aumento de preços em oferta já escassa e concorrida, na medida em que os leitos - hoje comprados pelo SUS - seriam transformados em leitos de melhor acomodação e os profissionais médicos fora do SUS ou com carga horária disponível, nele não se disporiam a entrar; (iii) em tese, os médicos que atendem as 'classes diferenciadas' e que pleiteiam diferença de classe já não atendem no SUS, por respeito à ética profissional e pela proibição legal de cobrança financeira ao paciente, não incorrendo, portanto, em nenhuma economia de recursos; (iv) os leitos considerados diferenciados ou de melhor acomodação já não são adquiridos pelo SUS, enquanto pertencentes a esta natureza, o que portanto e novamente, também não proporcionaria economia de recursos financeiros; (v) seria elevado o risco de 
diferenciação de um número excessivo de leitos, tornando insuficiente a, já escassa, oferta para o sistema público.

Ao considerar a moderação da demanda, a hipótese de aumento dos preços das ações e serviços de saúde, pagos por desembolso direto, acarretaria uma redução, produzindo a partir daí, reposicionamento e suposto equilíbrio nos preços. Não se trata de premissa simplista. Para os que consideram a diferença de classe um moderador da demanda, há hipóteses contrárias que devem ser consideradas: (i) a falta de acesso aos médicos ou aos leitos hospitalares pode aumentar o número de óbitos por desassistência ou de internações de emergência e urgência; (ii) a ociosidade de equipamentos médicosanitários faz alavancar os preços unitários dos procedimentos; (iii) o mercado poderia induzir a procura de ações e serviços de saúde como forma de equilibrar as remunerações no patamar que é pretendido - até porque a procura pelos bens da saúde dá-se pela prescrição e não pela livre iniciativa do paciente; (iv) a moderação de demanda não é bem vinda nos casos em que é essencial a detecção precoce da doença.

E mais, no Brasil, ao que se percebe no SUS ou nas operadoras de plano/seguro de saúde, não há consumo excessivo, ao contrário há escassez na oferta. Aqueles que não podem pagar pela pouca oferta existente restaria a desassistência, aos que podem pagar restaria a submissão às taxas médico-hospitalares.

Com a permissão para o uso da figura de linguagem: este é um filme que os brasileiros já assistiram e não gostaram.

\section{Autorização de internação hospitalar X diferença de classe}

É com a ponderação entre a escassez de recursos e o direito à saúde que o SUS atua e por isso, filiou-se à Medicina Baseada em Evidências (MBE) e adotou a formulação de Protocolos Clínicos e Diretrizes Terapêuticas (PCDT), que segundo o STF, consistem num conjunto de critérios que permitem determinar o diagnóstico de doenças e 0 tratamento correspondente, com os medicamentos disponíveis e as respectivas doses. Este é um controle para a formulação de políticas e programas, a consideração da melhor evidência científica e seu custo-benefício para a incorporação no SUS, tudo para atender ao princípio do acesso universal e da igualdade que se busca formas eficientes de atuação. 
$\mathrm{Na}$ busca de evidências que sejam adequadas à realidade sanitária interessam especialmente os dados do sistema de Autorização para Internação Hospitalar (AIH). A AlH, apresentada pela Portaria n $113 / 97$ definiu como padrão de atendimento no SUS, a internação em enfermaria, com sanitários e banheiros em quantidade adequada ao número de leitos, garante a gratuidade total da assistência prestada, sendo proibida cobrança complementar a qualquer título. A AlH observa o princípio da igualdade na prestação positiva do direito à saúde, permite o controle financeiro, acumulam os dados acerca de internações hospitalares feitas em cada unidade hospitalar, município, região de saúde, estados, regiões geográficas e país.

Eventual admissibilidade da diferença de classe, além da ruptura da lógica constitucional para o sistema público de saúde, causaria: (i) transtornos ao controle exercido sobre as internações; (ii) danos aos estudos e avaliações epidemiológicos produzidos a partir dos registros dos sistemas da AlH e que fundamentam a tomada de decisão pelos gestores do SUS, nos municípios, estados, DF e União; e, (iii) prática de preços distintos à tratamentos idênticos, além de outros, imensuráveis em primeiro momento.

\section{Controle social}

A participação social é um dos princípios mais caros ao SUS e está previsto na lei n. 8.142/90. Trata-se do grande diferencial do sistema nacional quando comparado aos demais sistemas universais no mundo.

A participação social na elaboração dos instrumentos de planejamento na saúde traz qualidade, controle, avaliação orçamentário-financeira, adequação das ações e serviços às realidades sanitárias locais. Portanto, com a admissibilidade da diferença de classe, a participação social quer na formulação da política de saúde, quer no controle exercido, seria desprestigiada e teria esvaziada a sua função. Não é verdadeira a máxima: exige-se mais qualidade pelo que se paga, uma vez que os Conselhos de Saúde, não remunerados, lutam pela consecução do direito à saúde há 25 anos, com qualidade e acesso isonômico, respeitado o princípio da gratuidade no SUS. 


\section{Renúncia fiscal}

Outro item que não pode ser afastado do debate diz da renúncia fiscal - que privilegia aos financeiramente favorecidos e consequentemente, discrimina os que não o são. $\mathrm{Em}$ eventual admissibilidade da diferença de classe, usuários desta modalidade, quando de suas declarações anuais de renda e despesas teriam restituídas suas despesas efetivadas em co-pagamento? Em caso positivo, remete ao pensamento de que o próprio Estado Brasileiro pagou pela acomodação diferenciada e o médico escolhido, o que agravaria o quadro já existente de discriminação social e de subfinanciamento da política pública de saúde.

\section{Conclusão}

Muitos outros quesitos poderiam ser incluídos ao rol que fundamenta a impossibilidade da admissão da diferença de classe, tais como: (i) o objeto pretendido pelo Cremers no RE 581488 é diferente daquele analisado nas decisões existentes no STF sobre o assunto; (ii) trata-se de interesse corporativo e não há manifestação favorável da sociedade acerca do pretendido; (iii) o direito à saúde não pode ser compreendido exclusivamente como direito à assistência hospitalar; e muitos outros, todavia, cumpre, em resumo e para fins de conclusão, ater-se aos que foram expostos neste ensaio.

A diferença de classe contraria os princípios constitucionais de acesso universal, integralidade e isonomia na consecução do direito à saúde. Também contraria toda a legislação sanitária - quer seja para a atuação da iniciativa pública, quer seja para a iniciativa privada. Contraria o modelo organizativo do sistema público de saúde, inspirado na solidariedade e que tem na lei, de forma expressa e inequívoca, o tratamento igualitário entre os cidadãos e a gratuidade das ações e serviços de saúde ofertados à população - 0 que não pode ser posto em dúvida.

Sua admissibilidade oferece ao SUS riscos de enfraquecimento ainda maiores, além de confrontar os anseios sociais por serviços públicos de qualidade. Neste ponto cabe reconhecer que o SUS tem problemas estruturais a serem enfrentados e neste caso, o nó górdio refere má remuneração dos serviços profissionais e dos estabelecimentos hospitalares. Todavia, este desafio não pode ser atacado com formas de onerar o cidadão. Importa, sim, propugnar para que o SUS goze de custeio suficiente ao provimento das necessidades sociais, promovendo, por um lado, a assistência médica necessária à 
promoção, prevenção e recuperação da saúde do cidadão e, de outro, remunere a preços justos os serviços profissionais, de hotelaria, exames e procedimentos médicohospitalares.

Conclui ao indicar o quão é de responsabilidade a posição do STF quando da análise da questão que será, dentro em breve, levada ao Plenário da Casa. Citem-se, por oportuno, as palavras do Ministro Ayres Britto, em seu discurso de posse: "se ao Direito, cabe ditar as regras do jogo da vida social, mormente, as que mais, temerariamente, instabilizam a convivência humana, o Poder Judiciário é que detém o monopólio da interpretação e aplicação final do sistema de normas em que esse Direito consiste." (STF, 2012, p.4) E, por fim, salienta-se do mesmo discurso que o Poder Judiciário "não pode, nunca, jamais e sob nenhuma hipótese, perder a confiança da coletividade, sob pena de esgarçar o tecido da coesão nacional”. (STF, 2012, p.4).

\section{Referências bibliográficas}

BARCELlos, A.P. A Eficácia Jurídica dos Princípios Constitucionais: O Princípio da Dignidade da Pessoa Humana. Rio de Janeiro: Renovar, 2001.

Brasil. Supremo Tribunal Federal. Audiência Pública da Saúde. 2009. Disponível em http://www.stf.jus.br/portal/cms/vertexto.asp?servico=processoaudienciapublicasaude Acesso em: 15 de maio de 2014.

Brasil. Supremo Tribunal Federal. STA 175. 2009. Disponível em: http://www.sbdp.org.br/arquivos/material/742 STA-AgR\%20175\%20-

\%20Voto\%20Min.\%20Gilmar\%20Mendes.pdf Acesso em: 15 de maio de 2014.

Brasil. Supremo Tribunal Federal. Audiência Pública Mais Médicos. 2014. Disponível em: http://www.stf.jus.br/portal/cms/verNoticiaDetalhe.asp?idConteudo=249852 Acesso em: 15 de maio de 2014.

Brasil. Supremo Tribunal Federal. Audiência Pública Diferença de Classe. 2014. Disponível em: http://www.stf.jus.br/portal/cms/verNoticiaDetalhe.asp?idConteudo=263039 Acesso em: 20 de maio de 2014.

BRITO,

A. Discurso

de posse.

2012.

Disponível

em: http://www.stf.jus.br/arquivo/cms/noticiaNoticiaStf/anexo/DiscursoAyresBritto.pdf Acesso em: 10 de maio de 2014.

CUNHA, J. R. A. O Princípio da Proibição do Retrocesso Social e o Direito à Saúde no Brasil. Monografia apresentada ao curso de Especialização em Direito Sanitário da Fundação Oswaldo Cruz-Brasília como requisito parcial para obtenção do título de Especialista em Direito Sanitário. Brasília; 2010. 
DERBLI, F. O Principio da Proibição de Retrocesso Social na Constituição de 1988. São Paulo: Renovar, 2007.

GLOPPEN, S. Social Rights Litigation as Transformation: South African Perspectives. Chr. Michelsen Institute Development Studies and Human Rights; 2005.

GLOPPEN, S.; JONES, P.; STOKKE, K. Democratising Development: the Politics of Socioeconomic Rights in South Africa. In: Social Rights Litigation as Transformation: South African Perspectives. Amsterdam: Nijhoff. Institute of Development Studies and Human Rights, p. 153-180, 2005.

LOPES, J. R. L.. As palavras e a Lei: Direito, ordem e justiça na história do pensamento jurídico moderno. São Paulo: EDESP; 2004.

VARGAS, K. El Desarrollo del Derecho a La Salud por parte de La Sala Constitucional y su Influencia en El Sistema Público de Salud en Costa Rica. 2010. Trabajo final de investigación aplicada sometido a la consideración de la Comisión del Programa de Estudios de Posgrado en Salud Pública para optar al grado y título de Maestría Profesional en Salud Pública con énfasis en Gerencia de la Salud. Universidad de Costa Rica. Ciudad Universitaria Rodrigo Facio, Costa Rica, 2010.

VIANA, S. M. et. al. Gratuidade no SUS: Controvérsias em torno do Co-Pagamento. 1998. Disponível em: http://www.ipea.gov.br/ppp/index.php/PPP/article/viewFile/109/111 Acesso em: 10 dez. 2014.

YEPES, R. U. A Judicialização da Política na Colômbia: casos, potencialidades e riscos. Revista Internacional de Direitos Humanos. São Paulo, v.6, n. 04, p. 49-65, 2007. 